\title{
COVID-19, VACUNACIÓN OBLIGATORIA $Y$ DERECHOS FUNDAMENTALES AL HILO DE LA SENTENCIA DEL TRIBUNAL EUROPEO DE DERECHOS HUMANOS VAVRICKA Y OTROS C. REPÚBLICA CHECA: UN FALSO DILEMA
}

\author{
Covid-19, mandatory vaccination and fundamental \\ rights under the Judgment of the European \\ Court of Human Rights Vavricka and others \\ c. Czech Republic: a false dilemma \\ ESTHER GONZÁLEZ-HERNÁNDEZ \\ Universidad Rey Juan Carlos \\ esther.gonzalez@uric.es
}

\section{Resumen}

El presente paper analiza una de las cuestiones más debatidas desde que se declarase la pandemia mundial por COVID-19: la consecución de una vacuna eficaz como la mejor fórmula de combatir el contagio y que permita el regreso a la normalidad. Si bien

1 La presente investigación se ha desarrollado en el marco del proyecto Good Governance for the Sustainable Development Goals. Programa Interuniversitario en Cultura de la Legalidad (ON TRUST-CM), Investigador principal: Manuel Villoria Mendieta, catedrático de Ciencia Política. URJC, Entidad Financiadora: Ayudas destinadas a la realización de Programas de Actividades de I+D entre grupos de investigación de la Comunidad de Madrid en Ciencias Sociales y Humanidades, cofinanciada con el Fondo Social Europeo. 
la reflexión que se aporta en estas páginas se desarrolla desde parámetros algo alejados de lo usual en la doctrina constitucionalista, después de una reflexión profunda y de la lectura de algunos textos de carácter científico-experimental sobre tres cuestiones fundamentales: cómo se han desarrollado las actuales vacunas, sus posibles (o) inciertas consecuencias futuras en la salud de los receptores y su verdadera efectividad en el control de la transmisión de la enfermedad y la consecución de la denominada inmunidad de rebaño.

\section{Palabras clave}

Covid-19; pandemia; vacunación obligatoria; derechos fundamentales.

\section{Abstract}

This paper analyzes one of the most debated issues since the world pandemic was declared by Covid-19: the achievement of an effective vaccine, as the best formula to combat contagion and that allows a return to normality. Although, it does so from parameters somewhat remote from what is usual in doctrine, after deep reflection and reading some texts of a scientific-experimental nature on how current vaccines have been developed, their possible (or not) future consequence on the health of the recipients and its true effectiveness. in controlling the transmission of the disease and achieving a true herd immunization.

\section{Keywords}

COVID-19; pandemic; compulsory vaccination; fundamental rights. 


\section{SUMARIO}

I. INTRODUCCIÓN. II. DILEMA $1:$ : LAVACUNADE LA COVID-19 ES UNA «VACUNA» EN EL SENTIDO TRADICIONAL DEL TÉRMINO? III. DILEMA 2: ¿̇ES POSIBLE LA VACUNACIÓN OBLIGATORIA EN ESPAÑA?: 1. ¿̇Restricciones o medidas preventivas son lo mismo que obligatoriedad de la vacunación? 2. Salud pública y la sentencia del TEDH en el caso Vavricka y otros c. República Checa. IV. DILEMA 3: EL SUPUESTO CONFLICTO ENTRE DERECHOS: 1. El derecho a la protección de la salud y sus variantes en el derecho comparado y en España. 2. Responsabilidad y leyes de compensación por los daños y periuicios en la salud producidos por las vacunas. V. CONCLUSIONES. BIBLIOGRAFíA.

Dilema: situación en que es necesario elegir entre dos opciones igualmente buenas o malas. Argumento formado por dos proposiciones contrarias disyuntivamente, de tal manera, que, negado o concedida cualquiera de las dos, queda demostrada una determinada conclusión (RAE, 2021).

\section{INTRODUCCIÓN}

El 14 de marzo de 2020 se declaró en España el estado de alarma por COVID-19, aunque esta declaración ya estaba en la mente de los españoles desde que el 10 de marzo la Comunidad de Madrid decidiera suspender toda actividad lectiva. Se decreta, así, un confinamiento domiciliario que se extendió hasta el 22 de junio y en el que sucedió de todo lo inimaginable, a pesar de que desde diciembre de 2019 ya se sabía de la existencia de un nuevo virus de graves consecuencias para la salud. Situaciones que se tornaron, en la mayoría de los casos, en decisiones de gran calado constitucional y de máxima gravedad en lo que se refiere al desarrollo de los derechos fundamentales contenidos en la CE/78 y otras cuestiones conexas.

Desde entonces, todo lo acaecido ha puesto a prueba los parámetros de trabajo e interpretación con los que se venía trabajando por las jurisdicciones ordinarias y constitucionales en la defensa de los derechos fundamentales, hasta, incluso, cierto desdibujamiento de las líneas y contornos básicos del «contenido esencial» de algunos derechos fundamentales. De la misma manera que el clásico «conflicto entre derechos» ha pasado a ser un conflicto entre derechos y situaciones de protección del bien común, bien superior, interés superior o interés general, en términos de 
salud pública y/o colectiva; términos ciertamente difusos que se insertan en la categoría de "conceptos jurídicos indeterminados». Esto no hace sino complicar aún más una situación, ya de por sí ciertamente complicada en su tratamiento jurídico. No hay conflicto de derechos porque el tan cacareado derecho a la salud no existe así enunciado. No hay Constitución que lo predique de semejante modo por imposibilidad material de garantizar la salud. La propia lógica del ser humano hace imposible descartar la enfermedad y garantizar la salud absoluta. Primeramente, porque del mismo se puede predicar tanto su dimensión individual como colectiva dejando dudas de si una puede superior a la otra y, en segundo lugar, porque, por mucho que se le quiera hacer pasar por un «cuasi-derecho fundamental básico y de primer orden o generación", no lo es como tampoco es alegable en amparo, en caso de supuesto conflicto.

El conflicto no está entre derecho-derecho (de la Sección 1 del capítulo II del título I), sino en derecho a la libertad o a la integridad física o moral o a la libertad ideológica, etc. y un principio rector; el de la protección de la salud, pues el art. 43 CE continúa afirmando: "Compete a los poderes públicos organizar y tutelar la salud pública a través de medidas preventivas y de las prestaciones y servicios necesarios». Aunque este precepto menciona la necesaria tutela de la «salud pública» y pudieran existir motivos por los que podría forzar al máximo la interpretación de esta segunda parte del art. $43 \mathrm{CE}$, desde el punto de vista literal este precepto solo permite a los poderes públicos organizar medidas preventivas y presta los servicios necesarios para la tutela de la salud pública. La cuestión es si podría argüirse que los poderes públicos pueden obligar a la vacunación obligatoria. Una primera interpretación literal y sistemática induce a una respuesta negativa. Por lo que habrá que realizar un análisis o interpretación posterior de tipo histórico y ontológico de esta previsión constitucional.

De esto versarán las siguientes páginas en el contexto español, si bien con las necesarias referencias al derecho comparado, para un adecuado entendimiento de una cuestión de enjundia, sin duda, ya de por sí lo suficientemente compleja en el debate público.

Estamos, quizá ante una situación muy similar a la que se produjo durante el confinamiento domiciliario en que ya varios constitucionalistas señalaron ciertas dudas, pues se restringió con carácter general y cuasi absoluto el derecho a la libre circulación, amén de otros derechos concatenados como reunión, manifestación, educación, libertad religiosa, huelga y, por supuesto, la libertad contenida en el art. $17 \mathrm{CE}$. Cuestión que parece empieza a aclararse por la declaración la inconstitucionalidad del estado de alarma del decreto 463 basándose en que, si bien la situación era lo suficientemente grave como para adoptar alguna medida similar, las que se tomaron no se ajustaban a la Ley Orgánica 4/1981, de 1 de junio, de los estados de alarma, excepción y sitio. Habiendo admitido, también a trámite, el recurso de inconstitucionalidad presentado contra el decreto 926/2020, resuelto por STC 183/2021, de 27 octubre en un sentido muy similar. 
No obstante, y a pesar de estas decisiones, el tema sigue presente, si bien bajo otros parámetros como es la derivada de las medidas jurídicas aprobadas para combatir la pandemia por COVID-19 en materia del ejercicio de los derechos fundamentales como el derecho a la libertad personal, la libertad de circulación, a la reunión y manifestación, a la integridad física, a la libertad ideológica, etc., que en estas páginas vamos a analizar desde estrictos criterios jurídicos y en relación con la constitucionalidad o inconstitucionalidad de la imposición de la vacunación como obligatoria de forma expresa o implícita ${ }^{2}$. Analizaremos, pues, esta cuestión bajo tres supuestos dilemas.

\section{DILEMA 1: 2 LA VACUNA DE LA COVID-19 ES UNA «VACUNA» EN EL SENTIDO TRADICIONAL DEL TÉRMINO?}

Empecemos por concretar qué se exige y qué requerimientos son necesarios para poder hablar de inoculación de una "vacuna» desde el punto de vista de las ciencias experimentales. Sabemos, más o menos, con cierta precisión que un virus es una célula de información genética envuelta en una o varias proteínas que reconocen su receptor celular para fusionarse con la célula blanco (Klinger y Sánchez, 2000: 28). Por tanto, supone una amenaza para nuestra salud si nuestro sistema inmunitario, ese conjunto de células y moléculas que actúan coordinadamente para la defensa de nuestro organismo contra moléculas extrañas (ibid.), no actúa correctamente o se trata de virus leucocitróficos. Es decir, que hay enfermedades víricas que no se pueden combatir con las conocidas comúnmente como vacunas.

La comunidad científica considera que «los métodos de prevención disponibles actualmente son tres: Inmunizaciones, Profilaxis y Conductas de Evitación. De la combinación entre ellos [...] obtendremos una mayor protección» (Sánchez Bustelo, 2004: 2). Por tanto, la vacunación no es el único instrumento contra los virus, sino uno de los varios que se contemplan para alcanzar la inmunización, en función de la individual «situación vacunal de acuerdo a criterios de edad y otros antecedentes personales» (Sánchez Bustelo, 2004: 2). Es por esto que se han considerado medicamentos especiales, que se regulan por una legislación específica y concreta. Así, el Real Decreto legislativo $1 / 2015$, de 24 de julio, por el que se aprueba el texto refundido de la Ley de garantías y uso racional de los medicamentos y productos sanitarios, cuyo art. 45 regula las garantías de estas en el siguiente sentido: «1. Las vacunas y los productos biológicos utilizables como medicamentos estarán sujetos al régimen

2 Mucha ha sido la literatura sobre el tema que podríamos señalar, pero nos limitaremos a señalar, entre otros, el monográfico de El cronista del Estado Social y democrático de Derecho (2020), núm. 86/87 (marzo-abril): «El coronavirus y otros problemas», algunos de cuyos artículos mencionaremos en estas páginas. 
de éstos con las particularidades previstas en esta ley o que se establezcan reglamentariamente según su naturaleza y características de aplicación propia...». A esto, el Real Decreto 1345/2007 define como medicamento inmunológico a las vacunas, toxinas, sueros y alérgenos.

En definitiva:

[...] científicamente, las vacunas se definen como unas medidas profilácticas tendentes a inmunizar a un individuo frente a la aparición de una concreta enfermedad. Con la vacuna, que produce una infección fingida, se pretende que la persona vacunada pueda vencer a una infección real mediante una respuesta defensiva de su propio sistema inmunitario, produciendo anticuerpos específicos contra el agente infeccioso. [...] la vacunación, por su contrastado alto grado de eficacia, bajo coste y simplicidad de aplicación, ha sido y es, sin duda, uno de los medios más adecuados para prevenir las enfermedades y mejorar el nivel de la salud colectiva (Martín Ayala, 2014: 169 y 170).

Estas precisiones de partida tienen su explicación, pues, a menudo, los juristas abordamos el estudio de una cuestión desde el enfoque estrictamente jurídico, olvidando que el «saber», y más el científico-experimental, debe adecuarse, en la medida de lo posible, a una valoración transversal de la cuestión. Esto nos obliga a fijar con claridad una serie de conceptos previos provenientes de otras ramas del saber sobre los que después formularemos las objeciones jurídicas que procedan, si es que proceden.

A este respecto, la considerada "vacuna» contra la COVID-19 resulta, a simple vista, una «vacuna» un tanto particular porque si bien existen otras vacunas que necesitan otra dosis de recuerdo (v. gr. el tétanos), en el caso que analizamos resulta que, a pesar de las varias dosis vacunación, se sigue siendo exigible mantener la distancia de seguridad y el uso de la mascarilla, la ventilación de espacios cerrados, etc. Es decir, que la aplicación de la lógica de los profanos en inmunología induce a pensar, a priori, que la vacuna contra la COVID-19 no es 100\% efectiva, como es el caso de las vacunas contra la viruela, las paperas, la tuberculosis, etc.

Es más, existe una clara diferencia entre las vacunas conocidas hasta la fecha o de vector viral que usan un virus inofensivo que ha sido modificado, es decir, que no puede replicarse y causar enfermedades y se administran en una sola dosis. La propia OMS define a las vacunas como una activación:

[...] de las defensas naturales del organismo para que aprendan a resistir a infecciones específicas, y fortalecen el sistema inmunitario. Tras vacunarnos, nuestro sistema inmunitario produce anticuerpos, como ocurre cuando nos exponemos a una enfermedad, con la diferencia de que las vacunas contienen solamente microbios (como virus o bacterias) muertos o debilitados y no causan enfermedades ni complicaciones ${ }^{3}$.

3 URL: OMS https://bit.ly/3nzo8dK, fecha de consulta: 12 de octubre de 2021. 
Sin embargo, en el caso las vacunas contra la COVID-19 solo son de "vector viral» la de Johnson \& Johnson, siendo de ácido ribonucleico mensajero (ARNm) en Pfizer y Moderna. Las vacunas de ARNm (mRNA, por sus siglas en inglés) contienen ácidos nucleicos, que son los componentes básicos de todas nuestras células. El ARNm lleva instrucciones dentro de una capa de lípidos o una burbuja de grasa que le dice a las células que produzcan piezas inofensivas de proteína en "picos» que se encuentran en el SARS-CoV-2. Una vez que se crea la proteína, el sistema inmunológico la identifica como una molécula extraña y produce anticuerpos que pueden adherirse al virus. Estos anticuerpos, en teoría, deberían proteger de contraer la COVID-19. Pues el ARNm lo que hace es reproducir el código genético del virus de forma artificial, que se introduce en el organismo para que el sistema inmunológico lo identifique en caso de contagio y pueda combatirlo. Pero la clave está en que este tipo de "vacunas» tan novedoso, que, si bien llevan tiempo investigándose, no habían finalizado los ensayos clínicos en humanos. Las vacunas de ARNm no contienen partes vivas o muertas del virus. Por ello, el llamado "ARN mensajero" se desvanece y desaparece, pero no en 60 milésimas de segundo, sino que se multiplica por 60 y se desconocen los efectos que este tiempo de exposición al ARNm puede producir en el ADN y, además, como la protección, se desvanece con el tiempo.

Por tanto, además de no corresponderse con lo que veníamos entendiendo por una vacuna, es decir, la inoculación de una parte mínima viva del virus, pero muy atenuada y debilitada, los ensayos clínicos llevados hasta la fecha no se sabe si son fiables. En este punto conviene apuntar unas breves consideraciones científicas respecto del proceso considerado eficaz y seguro de investigación y aprobación de una vacuna por la comunidad científica. Así, lo usual es hablar en 4 fases en los ensayos clínicos de vacunas, siendo la cuarta la de monitorización e información continua sobre su uso y los posibles efectos adversos y la inmunidad a largo plazo. Así lo reconoce la Agencia Española para el Medicamento:

[...] comienzan los ensayos clínicos, donde las vacunas se prueban en personas voluntarias. Estas pruebas ayudan a confirmar cómo funcionan las vacunas y, lo que es más importante, a evaluar su seguridad y eficacia protectora. Los ensayos clínicos se clasifican en cuatro fases:

— Ensayo clínico de Fase I, donde se comprueba inicialmente que el fármaco es seguro.

- Ensayo clínico de Fase II, donde se empieza a comprobar si el fármaco funciona como se esperaba y se realiza una búsqueda de la dosis más adecuada y del intervalo entre dosis.

- Ensayo clínico de Fase III, donde se verifican de forma robusta los aspectos de seguridad y eficacia del fármaco.

- Ensayo clínico de Fase IV o estudios de seguimiento, donde se examinan los efectos a largo plazo una vez el medicamento se ha comercializado. 
El desarrollo estándar de una vacuna es un proceso largo y los estudios se realizan en pasos secuenciales que suponen una media de entre cuatro y siete años. Pero el desarrollo de las vacunas frente a la COVID-19 se ha acelerado enormemente ${ }^{4}$.

Es precisamente por esta cuarta fase por lo que la aprobación de las vacunas puede tardar incluso años en completarse, ya que debe transcurrir un periodo de tiempo suficiente para que los sujetos reaccionen a la inoculación. Es por esto que la propia Organización Mundial de la Salud apunta: «Como todos los medicamentos, las vacunas pueden causar efectos secundarios leves — por ejemplo, fiebre baja, dolor o enrojecimiento en el lugar de inyección-, que desaparecen espontáneamente a los pocos días. Raramente producen efectos secundarios más graves o duraderos: la probabilidad de sufrir una reacción grave a una vacuna es de uno entre un millón», pero eso no significa que las vacunas no deban someter «una vigilancia continua para garantizar su inocuidad y detectar posibles efectos adversos $»^{5}$, por ejemplo a través del sistema VAERS, establecido en 1990, para detectar posibles problemas de seguridad en las vacunas autorizadas para uso en los EE. UU. administrado conjuntamente por los Centros para el Control y la Prevención de Enfermedades (CDC), entre otros, que afirman: "Es muy poco probable que después de recibir cualquier vacuna, incluida la vacuna contra la COVID-19, se produzcan efectos secundarios graves que causen un problema de salud a largo plazo» ${ }^{6}$. Tan solo una pequeña matización: probable significa que "sin ser seguro es muy posible que se cumpla» (RAE) y posible significa "que puede ser o suceder» (RAE).

En el caso de España, la Agencia Española del Medicamento, en su último informe de 3 de octubre de 2021, ha relatado las reacciones producidas antes por la vacuna de la COVID-19:

- Comirnaty (BioNTech/Pfizer): eritema multiforme, parestesias/hipoestesias, astenia, letargia, disminución del apetito y sudoración nocturna. Tras la evaluación de la información disponible, se ha concluido que no puede establecerse una relación causal entre la administración de esta vacuna y la aparición de glomerulonefritis/síndrome nefrótico, ni de trastornos menstruales.

- Spikevax (Moderna): eritema multiforme. Tras la evaluación de la información disponible, se ha concluido que no puede establecerse una relación causal entre la administración de esta vacuna y la aparición de glomerulonefritis/síndrome nefrótico, ni de trastornos menstruales.

- Vaxzevria (AstraZeneca): trombocitopenia inmune.

- COVID-19 Vaccine Janssen: trombocitopenia inmune, tromboembolismo venoso y mielitis transversa.

4 https://bit.ly/3mgxBqF, fecha de consulta: 18 de octubre de 2021.

5 https://bit.ly/2ZkdOhb, fecha de consulta: 18 de octubre de 2021.

6 https://bit.ly/3jBOJWg, fecha de consulta: 21 de octubre de 2021. 
Añade que, hasta el 3 de octubre de 2021, se han administrado en España 70.186 .758 dosis de vacunas frente a la COVID-19, habiéndose registrado 46.573 notificaciones de acontecimientos adversos, que suponen $0,6 \%$, es decir, 66 notificaciones por cada 100.000 , entre las comunicadas y, en que es indicativo que el $71 \%$ han sido comunicadas por profesionales sanitarios y solo el $29 \%$ por ciudadanos. Además, la mayoría de las notificaciones corresponden a mujeres (74\%) y a personas de entre 18 y 65 años (88\%). De estas 46.573 notificaciones de acontecimientos adversos, 9.430 fueron consideradas graves, es decir que requirieron hospitalización o una discapacidad significativa o persistente, o a una malformación congénita, peligro para la vida ${ }^{7}$.

Por tanto, la investigación sobre las vacunas es fundamentalmente un proceso largo, no especialmente difícil o costoso a nivel científico, pero sí requiere de tiempo y mesura, además de tamaños de muestra apropiados. Recuerdan Marrugat, Vila, Pavesi y Sanz (2006: 267) que:

[...] el diseño de un proyecto de investigación debe incluir la estimación del tamaño de la muestra a utilizar. De este modo, el investigador se ve obligado a precisar la magnitud y la dirección de sus hipótesis principales de trabajo. La estimación del tamaño muestra puede considerarse, por lo tanto, un instrumento del que dispone el investigador para evaluar la factibilidad y la necesidad de recursos de su proyecto. En el cálculo del tamaño muestral, la utilización de hipótesis verosímiles deberá prevalecer sobre otros intereses de los investigadores como las posibilidades económicas, la disponibilidad de pacientes u otros. Cabe recordar que no es ético realizar un estudio con un tamaño de muestra que no ofrezca un poder estadístico suficiente, ya que, desde el punto de vista de la metodología científica, el diseño no es adecuado.

No seré yo la que determine si el número de muestras tomadas ha sido suficiente ${ }^{8}$, pues ello parece una cuestión harto compleja, si bien podría argüirse que no ha sido lo suficientemente explicada.

Por tanto, el tema es aún más complejo de lo que se imaginaba en un principio, pues si la vacuna no va a garantizar de forma efectiva una inmunidad total frente a la enfermedad, ¿qué sentido tiene plantear su obligatoriedad? Ciertamente, ninguna vacuna asegura la inmunidad al 100 cien por cien, pero en el caso de la COVID-19, las noticias de que sea necesaria una tercera dosis ${ }^{9}$, además

7 Agencia Española del Medicamento, «9० Informe de Farmacovigilancia sobre Vacunas COVID-19» - Agencia Española de Medicamentos y Productos Sanitarios (aemps.gob. es)» (URL: https://bit.ly/3mkwO8w, fecha de consulta: 20 de octubre de 2021.

8 Para ello la propia OMS ya publicó el estudio de S. K. Lwanga y S. Lemeshow «Determinación del tamaño de las muestras en los estudios sanitarios. Manual práctico. Metodología Epidemiológica y Estadística», Ginebra (URL: https://bit.ly/2ZtkWsa., fecha de consulta: 18 de octubre de 2021).

9 Ya en proceso en España (URL: Vacunación COVID-19 Gobierno de España (vacunacovid.gob.es), fecha de consulta 18 de octubre de 2021). 
de su alta mutabilidad, hace presagiar que no está siendo tan efectiva como se pensaba. La propia OMS, el 7 de octubre de 2021 señalaba:

Debido a que las vacunas contra la COVID-19 se han desarrollado hace tan solo unos meses, aún se desconoce la duración de la inmunidad que confieren y hay que seguir investigando para responder a esta pregunta. Sin embargo, hay datos alentadores que indican que la mayoría de las personas que se recuperan de la enfermedad adquieren una inmunidad que protege contra una nueva infección, al menos durante un cierto tiempo, si bien aún se está determinando en qué grado y con qué duración ${ }^{10}$.

Por tanto, cuando hablamos de vacunación obligatoria como garantía de la salud pública o colectiva frente a la más que segura conculcación de varios derechos fundamentales, no estamos frente a un verdadero dilema, porque ise puede hablar de vacunación obligatoria en aras de la salud pública cuando no se tiene un alto porcentaje de efectividad y podría comportar riesgos para la salud por falta de los pasos científicos necesarios para dar por terminada una investigación desde criterios de seguridad? Parece difícil de sostener. Si la finalidad de una vacuna siempre ha sido conseguir una inmunización cercana al 100 por cien y esta, en el caso de la COVID-19, no lo ha conseguido, ni se han seguido las fases y tiempos de observación de las vacunas, no parece que se pueda afirmar sin más que es fiable y que garantiza la tan ansiada inmunidad de rebaño que no parece deberse solo a la vacunación, sino al uso de mascarillas, combinado con el mantenimiento de la distancia interpersonal, una mayor atención a la limpieza e higiene de servicios públicos, a la ventilación para evitar el contagio por aerosoles, a la limitación de aforos, la eliminación de ciertas prácticas como la costumbre española de compartir platos, etc.

No hay dilema, porque si la «vacuna» o «fórmula de refuerzo del sistema inmunológico» no parece conseguir dicha inmunización cuasi total y, además, pertenece a una familia de virus de rápida mutación como la gripe, ¿por qué imponer su vacunación obligatoria si con ello no se va a conseguir la práctica erradicación de la enfermedad como ocurrió con la viruela o las paperas?

Por tanto, cuando tratamos el tema de la obligatoriedad de las vacunas, lo primero es diferenciar entre tipos de vacunas, para poder determinar en cada una de ellas individualmente los principios jurídicos aplicables que permitirían defender su obligatoriedad. Así, siempre deberán tenerse en cuenta los principios de seguridad juridica, riesgo, precaución y responsabilidad y reconocimiento de un principio de compensación por daños y perjuicios en la salud. También será determinante el marco regulatorio: constitucional, legal, nacional y supranacional de cada Estado, que obviamente no es el mismo, junto con los tipos de colectivos sobre los que podría argüirse una mayor necesidad de su vacunación obligatoria: personal sanitario, fuerzas y cuerpos de seguridad del Estado, docentes, etc.

$\overline{10}$ OMS (https://bit.ly/3GtrbfU, fecha de consulta: 18 de octubre de 2021). 


\section{DILEMA 2: ¿̇ES POSIBLE LA VACUNACIÓN OBLIGATORIA EN ESPAÑA?}

Estamos, pues, ante el dilema número 2: ¿es posible imponer la vacunación obligatoria en España? Recuerda Miguel Presno que, en Italia, el 6 de abril de este año 2021, las autoridades sanitarias regionales preguntaban a los sanitarios que no estaban vacunados cuál era el motivo, ya que hay quien no podía inmunizarse por razones de salud y otros no requerían la inyección porque han pasado recientemente la infección. Al resto los invitaban a ponerse la vacuna y los que la rechazasen voluntariamente entraban en la rueda de sanciones. Primero se les relegará a otras funciones -incluso de menor rango-, para que no trabajasen en contacto con los pacientes. Si esto no es posible, se les suspendería de empleo y sueldo, hasta el 31 de diciembre de este año» (Presno Linera, 2021) ${ }^{11}$. Junto a Italia, Francia ${ }^{12}$ y Grecia $^{13}$ también anunciaban que obligarían a sus sanitarios a estar vacunados frente a la COVID-19, tema que también se valora en Reino Unido, junto con la obligatoriedad de la vacunación frente a la gripe (WISE, 2021).

En general, los modelos frente a las enfermedades contagiosas son dos:

1. Información, recomendación y voluntariedad.

2. Obligación y, en consecuencia, sanciones.

En este último caso debe aprobarse una norma que así lo explicite. Este es el caso de Italia, que aprobó el Decreto-Legge 1 aprile 2021, n. 44 y que deja claro como: «En consideración a la situación de emergencia epidemiológica

11 En Italia se aprobó el Decreto-legge no 73, de 7 de junio de 2017 por el que las vacunas obligatorias y gratuitas pasaron de cuatro a doce: anti-poliomelitica; anti-difterica; anti-tetanica; anti-epatite B; anti-pertosse; anti Haemophilusinfluenzae tipo B; anti-meningococcica $\mathrm{B}$; anti-meningococcica $\mathrm{C}$; anti-morbillo; anti-rosolia; anti-parotite; anti-varicella. Unas vacunas que son un requisito para el acceso a guarderías y escuelas infantiles (de 0 a 6 años). Junto a esto, la Corte Costituzionale italiana resolvió en dos sentencias 268/2017 y la 5/2018, que las leyes que imponían un tratamiento médico o la vacunación no son incompatibles con el art. 32 de la Constitución italiana, pues su redacción es más adecuada a semejante decisión: «La República protege la salud como derecho fundamental de la persona e interés básico de la colectividad y garantiza asistencia gratuita a los indigentes. Nadie podrá ser obligado a someterse a un tratamiento médico, a menos que así lo establezca la Ley. La Ley no podrá en ningún caso violar los límites que impone el respeto a la persona humana».

12 Francia lo anunciaba el 12 de julio de 2021, incluyendo también a todos aquellos en contacto con personas vulnerables. Además, el 26 de julio se aprobó la necesidad de disponer de un documento acreditativo de vacunación para asistir a teatros, cines, festivales, cafés, bares, restaurantes, etc.

13 En Grecia la vacunación para los trabajadores de residencias de tercera edad y los sanitarios es obligatoria a partir del 1 de septiembre de 2021 . 
del SARS-CoV-2, hasta la completa implementación del plan a que se refiere el artículo 1, párrafo 457, de la Ley núm. 178, y en todo caso a más tardar el 31 de diciembre de 2021, con el fin de proteger la salud pública y mantener adecuadas condiciones de seguridad en la prestación de los servicios asistenciales y asistenciales, a los profesionales sanitarios y profesionales de la salud que desarrollen su actividad en el ámbito sanitario público y privado, social -Las instalaciones sanitarias y de bienestar social, las farmacias, las parafarmacias y los despachos profesionales están obligados a vacunarse gratuitamente para la prevención de la infección por SARS-CoV-2». Por tanto, la vacunación es un requisito imprescindible para el ejercicio de la profesión, y para el desempeño del trabajo realizado por los sujetos obligados. La vacunación mencionada en el párrafo 1 será obligatoria y podrá omitirse o aplazarse en caso de que se determine un peligro para la salud, en relación con condiciones clínicas específicas documentadas y certificadas de cada ciudadano individualmente considerado ${ }^{14}$.

Sin embargo, en España, la situación es bien distinta, pues no tenemos tradición de obligatoriedad respecto de las vacunas, por mucho que algunos mencionen el Decreto de 26 de julio de 1945 (entre otros: Beltran Aguirre, 2012: 13 y 17; Martín Ayala, 2014: 172 y Ruiz Saez, 2011) por el que el Reglamento para la lucha contra las Enfermedades Infecciosas, Desinfección y Desinsectación, en su art. 3 establecía respecto de la peste, el cólera, la fiebre amarilla, el tifus exantemático y la viruela, que: «La declaración de una enfermedad infecciosa es obligatoria a la menor sospecha, sin esperar la confirmación clínica y de laboratorio, extremo que no podrá alegarse como excusa cuando se sanciona el incumplimiento de aquélla»; momento en el que las autoridades sanitarias actuarán con la máxima celeridad, pudiendo «ordenar el aislamiento de los enfermos infecto-contagiosos» (art. 13), que, según art. 19 podrá realizarse en el domicilio o en un hospital e, incluso, a los enfermos crónicos en estado de infectividad podrá prohibírseles el ejercicio de determinadas profesiones. Es en el capítulo IV en que regula la posibilidad de vacunaciones preventivas, estableciendo que: «Serán obligatorias para todo ciudadano de nacionalidad española las vacunaciones contra la viruela y la difteria, siendo sancionada su falta de realización» (art. 21), pudiendo imponer la obligatoriedad de otras vacunas sancionadas por la ciencia (art. 22) ${ }^{15}$, pero hace falta insistir en que es una norma preconstitucional, que, además, se refiere a una serie de enfermedades

14 Sobre la obligatoriedad de las vacunas según los países merece la consulta de: BIRD \& BIRD \& COVID-19. HR Data Essentials. Vaccine guidance, (2021), 20 de septiembre (URL: https:/www.twobirds.com.in-focus.coronavirus, fecha de consulta: 28 de septiembre de 2021).

15 Dice el artículo 24: «La vacuna B.C.G. contra la tuberculosis debe fomentarse. El suministro de esta vacuna será gratuito y es obligado ...", y el 25 que: «La vacunación antitifo-paratífica, será obligatoria para todas las personas en contacto con enfermos o sospechosos de padecer dicha dolencia». 
muy concretas, que no son la COVID-19. Este es, pues, el segundo dilema que tampoco es tal.

\section{1. ¿̇RESTRICCIONES O MEDIDAS PREVENTIVAS SON LO MISMO QUE OBLIGATORIEDAD DE LA VACUNACIÓN?}

Salvo la norma de 1945 y algún caso aislado vía jurisprudencia, como la decisión judicial de 2010 del Juzgado de lo Contencioso Administrativo de Granada, de 24 de noviembre, que obligaba a la vacunación forzosa de 35 niños del sarampión en la Sierra de Albaicín, la Ley 14/1986, de 25 de abril, General de Sanidad, señala en el art. 10 que los ciudadanos tienen, entre otros, los siguientes derechos: al respeto a su personalidad, dignidad humana e intimidad (...) y a la información sobre los servicios sanitarios a que pueden acceder y sobre los requisitos necesarios para su uso. La información deberá efectuarse en formatos adecuados, siguiendo las reglas marcadas por el principio de diseño para todos, de manera que resulten accesibles y comprensibles a las personas con discapacidad. Ciertamente, los arts. 24 y 26 establecen «limitaciones preventivas de carácter administrativo, de acuerdo con la normativa básica del Estado», así como que "las autoridades sanitarias adoptarán las medidas preventivas que estimen pertinentes, tales como la incautación o inmovilización de productos, suspensión del ejercicio de actividades, cierres de Empresas o sus instalaciones, intervención de medios materiales y personales y cuantas otras se consideren sanitariamente justificadas». Lo que, obviamente, no es lo mismo que obligar a la vacunación. Además, todas estas medidas deberán estar justificadas desde la certeza de que se estén afectando derechos fundamentales básicos y esenciales para con ello conseguir el objetivo de proteger la salud colectiva. Es decir, los procedimientos deberán ser proporcionados, adecuados, necesarios, racionales e idóneos, además de darse a conocer con antelación.

Por su parte, la Ley 41/2002, de 14 de noviembre, básica reguladora de la autonomía del paciente y de derechos y obligaciones en materia de información y documentación clínica, señala, en su exposición de motivos, la importancia que tienen los derechos de los pacientes como eje básico de las relaciones clínico-asistenciales, tal y como ponen de manifiesto casi todas las organizaciones internacionales con competencia en la materia como Naciones Unidas, Unesco o la Organización Mundial de la Salud, la Unión Europea o el Consejo de Europa ${ }^{16}$.

16 En el Instrumento de Ratificación del Convenio para la protección de los derechos humanos y la dignidad del ser humano con respecto a las aplicaciones de la biología y la medicina, hecho en Oviedo el 4 de abril de 1997, se establece que se protegerá al ser humano en su dignidad y su identidad y garantizarán a toda persona, sin discriminación alguna, el respeto a su integridad y a sus demás derechos y libertades fundamentales con respecto a las aplicaciones de la biología y la medicina (art. 1) y que: «El interés y el bienestar del ser humano deberán prevalecer sobre el interés exclusivo de la sociedad o de 
Por tanto, se reconocen los derechos de los pacientes, como el derecho a la información, el consentimiento informado y la intimidad de la información relativa a la salud. Solo de este modo, el paciente o usuario tendrá derecho a decidir en verdaderas condiciones de libertad, al haber recibido la debida información entre las opciones clínicas disponibles.

\section{SALUD PÚBLICA Y LA SENTENCIA DEL TEDH EN EL CASO VAVRICKA Y OTROS C. REPÚBLICA CHECA}

En situaciones de crisis sanitaria parece que todo se resuelve acudiendo al viejo principio latino de salus publica suprema lex. Empecemos por señalar que no es lo mismo «salud pública» que «salud colectiva». El término público alude a la conocida como res pubblicae, mientras que colectiva se refiere a personas pertenecientes a determinado grupo o categoría. Pues bien, aunque la Ley 33/2011, de 4 de octubre, General de Salud Pública, que tiene como principal objetivo, entre otros, proteger y promover la salud de las personas, tanto en la esfera individual como en la colectiva, no exija la vacunación obligatoria, sí nos ayuda a perfilar el indeterminado concepto de «salud pública» como el conjunto de actividades organizadas por las Administraciones públicas, con la participación de la sociedad, para prevenir la enfermedad, así como para proteger, promover y recuperar la salud de las personas, tanto en el ámbito individual como en el colectivo y mediante acciones sanitarias, sectoriales y transversales a lo que añade que corresponde a la autoridad sanitaria estatal con carácter general, en el ámbito de sus competencias, la adopción de medidas sobre coordinación y ejecución de las actuaciones de salud pública consideradas en la presente ley, así como la adopción de cuantas medidas de intervención especial, de acuerdo con el art. 52, en materia de salud pública resulten precisas por razones sanitarias de urgencia o necesidad o ante circunstancias de carácter extraordinario que representen riesgo evidente para la salud de la población, y siempre que la evidencia científica disponible así lo acredite. En definitiva, serán principios generales de acción en salud pública, entre otros:

1. Principio de salud en todas las políticas: de carácter no sanitario que influyan en la salud de la población, promoviendo las que favorezcan los entornos saludables.

la ciencia» (art. 2) y que, según el art. 5, toda «intervención en el ámbito de la sanidad solo podrá efectuarse después de que la persona afectada haya dado su libre e informado consentimiento» que podrá ser retirado libremente. No obstante, en el art. 10.3 apunta que: «De modo excepcional, la ley podrá establecer restricciones, en interés del paciente, con respecto al ejercicio de los derechos mencionados en el apartado 2». 
2. Principio de precaución: que supone la constatación de indicios fundados de una posible afectación grave de la salud de la población, aun cuando hubiera incertidumbre científica sobre el carácter del riesgo.

3. Principio de riesgo y de pertinencia: las actuaciones de salud pública atenderán a la magnitud de los problemas de salud de acuerdo con los criterios de proporcionalidad, eficiencia y sostenibilidad.

4. Principio de seguridad jurídica y científica: las actuaciones en materia de salud pública se llevarán a cabo previa constatación de su seguridad en términos de salud.

5. Principio de responsabilidad y compensación por daños, por los posibles efectos secundarios adversos de las vacunas.

A estas normas se suma el Real Decreto Ley 8/2021, de 4 de mayo, por el que se adoptan medidas urgentes en el orden sanitario, social y jurisdiccional, que se aplicaría una vez finalizado el estado de alarma declarado por el Real Decreto 926/2020, de 25 de octubre, por el que se declara el estado de alarma para contener la propagación de infecciones causadas por el SARS-CoV-2, que contempla en su artículo primero que el Ministerio de Sanidad determinará los controles sanitarios necesarios a los que deben someterse los pasajeros que lleguen a España. Junto con las resoluciones de la Dirección General de Salud Pública, de 29 de junio, 11 de noviembre y 9 de diciembre de 2020, sobre la situación epidemiológica con respecto a la pandemia por COVID-19 y la resolución de 4 de junio de 2021, de la Dirección General de Salud Pública, relativa a los controles sanitarios a realizar en los puntos de entrada de España.

Por tanto, a pesar de esta última normativa y de la idéntica finalidad de la UE respecto del pasaporte Covid-19 ${ }^{17}$, la vacunación en España no es obligatoria. Es más, en el ámbito laboral está consolidada una línea interpretativa que rechaza, en términos generales, la vacunación obligatoria de los trabajadores, al menos mientras no se cambie la legislación vigente. Así, en el Real Decreto 664/1997, de 12 de mayo, sobre la protección de los trabajadores contra los riesgos relacionados con la exposición a agentes biológicos durante el trabajo se prevé (art. 8) que:

1. El empresario garantizará una vigilancia adecuada y específica de la salud de los trabajadores en relación con los riesgos por exposición a agentes biológicos, realizada por personal sanitario competente, según determinen las autoridades sanitarias en las pautas y protocolos que se elaboren... 3. Cuando exista riesgo por exposición a agentes biológicos para los que haya vacunas eficaces, estas deberán ponerse a disposición de los trabajadores, informándoles de las ventajas e inconvenientes de la vacunación. Cuando los empresarios ofrezcan las vacunas deberán

17 Recomendación (UE) 2020/912 del Consejo de 30 de junio de 2020 está procediendo también a la revisión de la Recomendación (UE) 2020/1475 del Consejo de 13 de octubre de 2020. 
tener en cuenta las recomendaciones prácticas contenidas en el anexo VI de este Real Decreto: El ofrecimiento al trabajador de la medida correspondiente, y su aceptación de la misma, deberán constar por escrito.

Parece claro, pues, que la vacunación frente a la COVID-19 es, con carácter general, una opción para los trabajadores y no una obligación, dado que no está asegurado que la vacunación impida el contagio a otras personas y, en consecuencia, el riesgo para la «salud pública» persista.

En esta línea cabe recordar que, de acuerdo con la Ley General de Salud Pública (art. 19.2): «Las Administraciones públicas, en el ámbito de sus respectivas competencias... c) Impulsarán otras acciones de prevención primaria, como la vacunación» y que el art. 54, si bien señala que se podrán adoptar cuantas medidas sean necesarias para asegurar el cumplimiento de la ley, no recoge entre estas expresamente la vacunación, sino que añade: «las medidas que se adopten deberán, en todo caso, respetar el principio de proporcionalidad». Hay, no obstante, una remisión a la Ley Orgánica 3/1986 que pudiera ser interpretada como una cláusula habilitante para la vacunación obligatoria de determinados colectivos, junto con el art. 4 que dispone como:

sin perjuicio de las medidas previstas en la Ley Orgánica 3/1986, de 14 de abril, de Medidas Especiales en Materia de Salud Pública, con carácter excepcional y cuando así lo requieran motivos de extraordinaria gravedad o urgencia, la Administración General del Estado y las de las comunidades autónomas y ciudades de Ceuta y Melilla, en el ámbito de sus respectivas competencias, podrán adoptar cuantas medidas sean necesarias para asegurar el cumplimiento de la ley....

Si bien esto no es más que lo que los juristas conocemos como un «cajón de sastre», que además viene matizado por la exigencia de que «las medidas que se adopten deberán, en todo caso, respetar el principio de proporcionalidad». Estamos, por lo general, ante un tipo de legislación que intenta prever lo imposible, porque es imposible saber a qué nuevas enfermedades víricas o bacteriológicas estaremos expuestos, cómo evolucionarán, su factor de contagio, su peligrosidad, etc. Por ello, estas normas que suelen contener cláusulas, fórmulas y redacciones muy abiertas e incluir varios «conceptos jurídicos indeterminados» que lo hacen todo más confuso, como las referencias constantes al «interés público», al «interés general», al bien común; fórmulas, en sí mismas, imprecisas o excesivamente permisivas de medidas de restricción o intervención forzosa muy genéricas, que no permiten perfilar nítidamente qué sería el «derecho a la salud pública o colectiva». Se trata, pues, de leyes que tratan de regular situaciones cuyas circunstancias y devenir futuros se desconocen, ya que los riesgos para la salud pública pueden venir por muy ignotas y diferentes vías (Cobreros Mendazona, 2020: 9).

Sarrión (2021), sin embargo, entiende que la previsión, per se, de la Orgánica 3/1986, puede constituir una base suficiente, junto con los arts. 25 y 26 de la Ley 
14/1986, de 25 de abril, General de Sanidad y el art. 54 de la Ley 33/2011, de 4 de octubre, General de Salud Pública (LGSP), al aludir a «motivos de extraordinaria gravedad o urgencia» que habilitarían para adoptar cuantas medidas sean necesarias para asegurar el cumplimiento de la ley como: a) la inmovilización y, si procede, el decomiso de productos y sustancias, b) la intervención de medios materiales o personales, c) el cierre preventivo de las instalaciones, establecimientos, servicios e industrias, d) la suspensión del ejercicio de actividades (Ley 14/1986, de 25 de abril, General de Sanidad). Por otra parte, junto al concepto de «salud pública» se suele acudir al denominado «derecho constitucional de excepción» (Sarrion, 2021) o derecho ordinario de necesidad, también denominado "derecho ordinario de excepción», que como el mismo autor apunta es contradictorio en sí mismo: si es ordinario no puede ser de excepción, pero que podría otorgar la cobertura legal necesaria para adoptar las decisiones de emergencia sanitaria, incluso cuando esta afecte a derechos fundamentales prescritos en la Constitución.

Este argumento de la «salud pública» está en la línea de la reciente sentencia del Tribunal Europeo de Derechos Humanos: la sentencia TEGC, de 8 de abril 2021, en que este se pronuncia sobre la vacunación obligatoria afirmando que esta: «Es necesaria en una sociedad democrática». Se trata del Caso Vavricka y otros $c$. República Checa, que se planteó ante el TEDH en 2015 (TEDH, 2020), es decir, mucho antes de la COVID-19. Lo que supone ya de partida un menoscabo para la validez de esta sentencia como elemento fundamentador de la obligatoriedad de la vacunación de la COVID-19, pero, además, la sentencia leída y analizada íntegramente no es, en absoluto aplicable, entre otros motivos porque se refiere a la vacunación obligatoria de niños frente a enfermedades bien conocidas, como polio, hepatitis $B$, tétanos, sarampión, paperas y rubeola, cuya eficacia está más que probada y cuyo conocimiento científico no es comparable, ni de lejos, con lo que se sabe a día de hoy, de la COVID-19. Además, tampoco conlleva un conflicto de derechos, pues solo se refiere a la privación del derecho a asistir a la formación preescolar de los menores pero, en ningún caso, colisionaría con el derecho a la educación, pues estos menores no estarían excluido del sistema de enseñanza obligatoria. Ciertamente, la República Checa argumentó el interés superior del menor, que traducía en el derecho del niño al disfrute del más alto nivel posible de salud en el sentido del art. 24 de la Convención sobre los Derechos del Niño de la ONU y adjuntaba la normativa checa que lo permitía ${ }^{18}$. A lo que el TEDH añadió:

- El carácter sensible del deber de vacunación infantil por el que los Estados tienen la obligación de colocar el interés superior del niño, y también el de

18 Ley constitucional 2/1993: arts. 4.7.1,16.1 31, 33 y 431; Ley de Protección de la Salud Pública (Ley 258/2000); Decreto 439/2000, de vacunación contra enfermedades infecciosas; Ley de educación (Ley 561/2004); Ley de infracciones administrativas (Ley 200/1990) y Ley de compensación por los daños a la salud derivados de la vacunación obligatoria (Ley 116/2020). 
los niños como grupo, en el centro de todas las decisiones que afecten a su salud y desarrollo.

- Protección de la salud de todos los miembros de la sociedad, en particular de aquellos que son especialmente vulnerables frente a determinadas enfermedades.

- Protección de la inmunidad colectiva.

- Y, sobre todo, que la obligación de vacunación se refería a diez enfermedades en las que la comunidad científica consideraba que la vacunación era eficaz y segura.

Por último, y esta es la segunda de las claves de una sentencia que avalaría la «vacunación obligatoria» junto con la evidencia científica probada de su alta efectividad, es el dato de que la República Checa cuenta con una ley de compensación del daño producido por los posibles efectos adversos de la vacuna.

\section{DILEMA 3: EL SUPUESTO CONFLICTO ENTRE DERECHOS}

El tercer dilema es si verdaderamente estamos ante un conflicto de derechos, es decir, será necesario, en primer lugar, comprobar si los textos constitucionales contemplan alguna referencia a la protección y tutela de la salud individual y colectiva, pues, psicológicamente cuando se trata de la «salud», quizá junto con la libertad, nuestro bien más preciado, las cosas a nivel jurídico resultan más complicadas.

\section{EL DERECHO A LA PROTECCIÓN DE LA SALUD Y SUS VARIANTES EN EL DERECHO COMPARADO Y EN ESPAÑA}

Bombillar Saéz y Pérez Miras (2015: 308-318) realizan un exhaustivo examen de esta cuestión, que me permitiré resumir en que hay varios grupos de Constituciones, como la francesa o la checa, que lo remiten a otras normas de carácter inferior. Otras que lo regulan de manera autónoma, como la italiana, que ya hemos comentado, o la portuguesa, cuyo art. 64 dice que «todos tienen el derecho a la protección de la salud», a lo que añade que en forma de «servicio nacional de salud universal y general». Otras, como la holandesa, prefieren expresarlo en forma de promoción de la salud. A diferencia de la de Estonia o la eslovena y la de Letonia, se refieren a cuidados médicos, de un modo muy semejante a la de Bulgaria, que explicita que «nadie puede ser obligado a recibir tratamiento médico, salvo en los casos previstos en la ley». Otras más tímidas, como la de Rumanía que se refiere a la toma de medidas necesarias para asegurar la higiene y la salud y la organización de una asistencia médica. En esta misma línea se sitúa, nuestra Carta Magna en su art. $43 \mathrm{CE} / 78$ : 
Se reconoce el derecho a la protección de la salud. Compete a los poderes públicos organizar y tutelar la salud pública a través de medidas preventivas y de las prestaciones y servicios necesarios. La ley establecerá los derechos y deberes de todos al respecto. Los poderes públicos fomentarán la educación sanitaria, la educación física y el deporte. Asimismo. facilitarán la adecuada utilización del ocio.

Si bien el teórico conflicto entre derechos es una entelequia, un nuevo dilema que se diluye y evapora a poco que se reflexione un poco sobre el tema. En primer lugar, porque no existe, por mera lógica, un «derecho a la salud». Nadie puede garantizar la salud ad eternum, porque ello va contra la condición humana que enferma y seguirá enfermando. A lo sumo, y como ya decíamos, los textos constitucionales que incluyen referencias a la salud lo hacen en términos de recoger el «derecho a la protección de la salud» en diferentes formas gramaticales, pero, salvo la Constitución húngara que no es aplicable, pues se refiere a otro supuesto (el de los alimentos transgénicos), o bien no la mencionan o bien lo hacen en el sentido de acoger un derecho de contenido social en boga después de la Segunda Guerra Mundial y que se traduce en garantizar un sistema sanitario estatal que asegure unos mínimos (o máximos, dependiendo de cuestiones presupuestarias) de asistencia a los ciudadanos en situaciones de enfermedad.

Este «derecho a la protección de la salud» en realidad no es un derecho fundamental, como sí lo son el derecho a la integridad física del art. $15 \mathrm{CE}$ o el derecho a la libertad: art. $17 \mathrm{CE}^{19}$, o el derecho a la libertad ideológica del art. 16, amén de derecho a la autonomía del paciente reconocido legalmente. Como también habría que tener en cuenta la vulneración del derecho a la libertad deambulatoria (STC 53/2002, FJ 14), que supondría la obligatoriedad del «pasaporte Covid», por ejemplo, en el ámbito de la UE basado en el sacrosanto principio de la libre circulación de personas, bienes y capitales y el espacio Schengen.

Es obligado recordar que la CE/78 asumió la "Teoría de las generaciones de derechos", inicialmente formulada por Karel Vasak (1977) y confirmada después en 1979 en la "Lección inaugural» del X Sección de Enseñanza del Instituto Internacional de Derechos Humanos. Por ello, el texto de 1978 contemplaba una estructura interna que los organiza en tres generaciones de derechos:

1. Derechos de primera generación o derechos y libertades civiles o de carácter político en la Sección $1^{\mathrm{a}}$, capítulo II del título I.

19 Recordemos que la STC 29/2008, FJ 7 in fine, distingue entre libertad como valor superior del ordenamiento jurídico que supone que la personas «gozan de autonomía para elegir entre las diversas opciones vitales que se les presentan». Es decir, que la jurisprudencia del TC no se refiere a la mera privación de libertad por el ingreso en prisión o detención ilegal. Es más, la jurisprudencia del TEDH sobre el art. 5, Convenio Europeo de Derechos Humanos, al respecto añade que es, además, necesario que se garantice el principio de seguridad jurídica, es decir, que las condiciones para su privación o restricción estén claramente definidas en la ley y que la ley sea precisa. 
2. Derechos de segunda generación o socio-económicos en la Sección 2a, capítulo II del título I.

3. Derechos de tercera generación de solidaridad o colectivos en el capítulo III del título I.

Será esta estructura y ubicación lo que determinará la mayor o menor efectividad, protección y garantías de los derechos e, incluso, su consideración como tal. Así, en el caso de los contenidos en el capítulo III, el artículo 53.3 CE modula sus garantías de protección, como es bien sabido, porque, en puridad, no los reconoce como «derechos públicos subjetivos», sino como una mera declaración de principios o aspiraciones.

Recordemos que, en materia de derechos durante el proceso de redacción de la Constitución de 1978, la UCD prefería una Constitución breve, centrada en la organización de poderes, si un largo catálogo de derechos (Herrero de Miñón, 1979: 80). Mientras, el PSOE no estaba dispuesto a renunciar a un texto con su parte dogmática ${ }^{20}$. Tanto para el PSOE como para los comunistas era obvio que:

la nueva Constitución española hay que dotarla de verdadero contenido democrático, a través de la declaración explícita y con carácter de vigencia desde su formulación constitucional de los derechos humanos fundamentales, civiles, políticos, económicos, sociales y culturales [...] se recogen, con todos los efectos naturalmente derivados, los derechos a la vida y a la integridad personal, libertad personal y seguridad; derechos de igualdad entre las personas, de expresión e información, de conciencia y religión, de residencia y emigración, asociación, reunión y manifestación, así como los de participación en la vida pública. Entre los derechos económicos, sociales y culturales, los de trabajo, huelga y libertad sindical, derechos garantizados a una sanidad, educación, vivienda y calidad de vida dignas, enseñanza básica y media gratuita y acceso a la universidad o estudios superiores en igualdad de oportunidades. Estos derechos no se formularán como una mera declaración de principios programáticos, sino que deberán establecerse al mismo tiempo, las garantías para su efectividad y su vigencia legislativa, entendiéndose directamente aplicables con la consiguiente derogación de cuantas leyes o preceptos se opongan a los mismos [se afirma en «La izquierda y la Constitución en abril de 1978 (Jiménez Villarejo, 1978: 77)].

Sin embargo, los representantes de UCD solo consideraban la necesaria alusión al respeto y sujeción a la Convención Europea de Derechos Humanos, sus Protocolos y la Carta Social Europea. La UCD quería una «Constitución utilitaria» frente a una "Constitución ideológico-programática» (Herrero de Miñón, 1979: 80), pero Peces-Barba logró imponer su criterio de elaborar una

20 Sobre esta cuestión puede consultarse el estudio más detenido de González Hernández, E., El debate constituyente sobre el Título I de la Constitución española de 1978, o la Constitución "cenada», Historia constitucional, 20, 2019 (https://bit.ly/3miYlH7, fecha de consulta: 20 de julio de 2021). 
Constitución larga y detallada, frente a la opinión de Herrero, que la prefería breve (Fernández Palmero, 2019), pero fue la UCD la que consiguió imponer sus posiciones más conservadoras y pecatas en materia de derechos gracias a su alianza con Fraga y Roca, lo que provocó la salida de la Ponencia del representante socialista que, como explica Powell, accedió, sin embargo, a firmar el texto definitivo (Powell, 2001: 22). Se empieza, por fin, a debatir el contenido concreto de cada uno de los derechos, redactando, ya sí, el Anteproyecto de Constitución, en el que solo se contemplaban dos categorías de derechos en su inicial título II, «De los derechos y deberes fundamentales»:

1. «De las libertades públicas» en el capítulo II (arts. 13 a 33).

2. «Principios rectores y derechos económicos y sociales» en el capítulo III (arts. 34 a 44).

Posteriormente, en el Pleno, en julio de 1978, la mayoría de los artículos se aprobaron siempre por 19 votos (los de UCD y AP) contra 17, y donde:

Herrero de Miñón volvió a insistir en la remisión de la "polémica parte dogmática» a los textos internacionales y, a pesar de que en la reuniones de la Ponencia la UCD no se opuso a las garantías de los principios rectores establecidas por el art. 48.3 del informe, el citado ponente se manifestó en contra de que la protección a estos derechos incluyera su alegación antes la jurisdicción ordinaria mediante los procedimientos establecidos en las leyes que los desarrollen (Freixes, 1984: 114).

Es en esta etapa donde comienzan las reuniones, siempre discretas, de los líderes de los partidos (Pérez Llorca, 2018: 58 y 59). A partir de aquí, es decir, a partir del 22 de mayo de 1978 la Constitución se gestó de noche y en interminables y frecuentes cenas entre los dos protagonistas del proceso constituyente: Abril Martorell y Alfonso Guerra. Reuniones en las que se desencalló el principal punto de desencuentro: la cuestión de los derechos sociales con la enmienda número 779 del Grupo de Unión de Centro Democrático, que reordena el título II, que pasa a ser ahora el título I con la rúbrica «De los derechos y deberes fundamentales». Es en este momento cuando el capítulo II pasa «a denominarse «De los derechos y libertades» y se divide en dos secciones: la primera tiene como rúbrica "De las libertades públicas»; y la segunda «De los derechos y deberes de los ciudadanos».

En definitiva, se acababa de delinear las líneas maestras del sistema de protección de los derechos y libertades de la Constitución española de 1978 y aparece la expresión: "principios rectores de la política económica y social» en el capítulo III, donde se recogieron los que inicialmente eran considerados derechos sociales y, entre ellos, el derecho a la protección de la salud, que deja de ser un derecho para pasar a convertirse en un principio rector, id est, informativo de los objetivos del Estado-gobierno. 
Por tanto, según esta sistemática, el tan cacareado "derecho a la salud» ni existe, ni sería un derecho, pues lo que la Constitución española recoge es el «derecho a la protección de la salud» y, por lo que hemos explicado ni tan siquiera es un derecho, por tanto, no habría derechos que ponderar. Herrero de Miñón bien claro tenía que:

[...] los principios rectores, tal y como aparecen en la Constitución española de 1978 (Título I, Capítulo 3o), se insertan en una tradición muy defectuosa iniciado en el texto de 1931, definitivamente acuñado en la Constitución irlandesa de 1937, y se difundió en la Lejano Oriente a partir de la birmana de 1948 y la hindú de 1950. Se trata, en síntesis, de unos valores que deben inspirar al legislador, a la Administración, e incluso al juez pero no pueden ser alegados ante los Tribunales para impugnar la constitucionalidad de una norma ni para pedir la tutela de un derecho, afirmaba taxativamente Herrero en la Comisión constitucional (Cortes Generales, 1979: 2026).

Quedaban, en su opinión, reducidos a meras declaraciones, a lo sumo con alcance programático e indicativo (Herrero de Miñón, 1979: 93). Es decir, un valor sin valor, si se me permite el juego de palabras. Ya que no se pudo aligerar el texto constitucional de una serie de afirmaciones, a juicio de Herrero de Miñón (1979: 93), poco operativas, se imponía rebajar la ambigüedad y retórica, negando carácter normativo a determinadas partes, id est, al capítulo III del título I, al distinguir entre «derechos» y meros «principios rectores», entre norma y mera emotividad. Quedaban, pues, reducidos a orientar o regir la política del Gobierno, pero de aquí a hablar de una obligación en firme... esto es, de corrección en profundidad del sistema económico para tender a la eliminación de las desigualdades sociales, había un paso más que no se dio en 1978.

Se podrá defender, como hacen algunos (Cierco Seira, 2020: 24 y Cobreros Mendazona, 2021: 8), que la frase del art. $43 \mathrm{CE} / 78$, «La ley establecerá los derechos y deberes de todos al respecto», permitiría entender la obligatoriedad de la vacuna. En nuestra modesta opinión hay varios argumentos a tener en cuenta. Primero, que en España, además de que no se constata una «previsible resistencia social» (Cierco Seira, 2020: 27), no existe una ley que así lo establezca. Recordemos que, siguiendo a este mismo autor (2020: 20-28), sobre esta cuestión los sistemas se pueden dividir en voluntarios, recomendados, condicionantes, obligatorios y forzosos: modelos que no son excluyentes entre sí. En el caso español el sistema es de recomendación. De ahí que se establezca, por tanto, un calendario vacunacional.

Pero es que, además, la genérica alusión a deberes no puede ser entendida sin más como "obligatoriedad», pues un "deber» es algo diferente que una acción obligatoria. Recordemos que, en el nivel constitucional, salvo el deber tributario, todos los demás tienen sus matices y sus excepciones. V. gr. el derecho-deber del servicio militar admitía la objeción de conciencia, el deber de acudir a las 
comisiones de investigación es solo de acudir no de contestar, porque ello entraría en colisión con el derecho constitucional a, por ejemplo, no declararse culpable de un delito. $\mathrm{O}$ el derecho-deber de los ciudadanos a participar en la Administración de Justicia, contra el que se pueden argüir determinadas causas justificativas que permitan su incumplimiento. Si a esto unimos que la literalidad de este precepto que añade: "organizar y tutelar la salud pública a través de medidas preventivas», poco de obligatoriedad se puede deducir cuando se habla de organización, tutela y medidas preventivas, pues la alusión a la «salud pública» de la Constitución española no es sino un objetivo al que estarían obligados en su promoción los poderes públicos, esto es, a la conformación y desarrollo de su sistema sanitario lo más eficaz y universal posible.

No obstante, supongamos que existiera un teórico conflicto entre derechos, que no es así, pues el art. 43 no puede ser alegado en amparo ante el Tribunal Constitucional como sí los arts. 15, 16 y 17, entre otros. Pero supongamos que se pudiese. Para resolver este hipotético conflicto deben aplicarse las reglas de ponderación de derechos que, entre otras cuestiones, exigen como cláusula previa que exista y se constate el principio de lex certa, esto es, unos mínimos de seguridad jurídica. Junto a esto, en cuanto ya a la concreta ponderación, el juicio será de comprobación de la:

- Necesidad: la constatación indubitada del presupuesto de hecho habilitante, que no es otro que la existencia de un peligro real, efectivo y que requiera una actuación urgente (Cobreros Mendazona, 2021: 13).

- Razonabilidad: es decir, la «justificación o motivación de las medidas que a su amparo se adopten» (ibid.: 13 y 14). Es innegable que puede existir riesgos para la salud, pues no se saben los efectos futuros de este nuevo proceder científico, alejado de los estándares de seguridad aceptados hasta la fecha, ¿es razonable poner a los ciudadanos ante ese riesgo de forma obligatoria?

- Idoneidad: si la vacunación no garantiza altos porcentajes de inmunización y sigue exigiéndose el uso de mascarillas en el interior, distancia interpersonal, ventilación, extremar las medidas de higiene y se desaconseja la realización de determinadas prácticas de grupo, ¿̨la doble pauta es idónea? Mejor aún, la triple pauta de la que ya comienza a hablarse, ¿no es más que un indicativo de que dicha "vacunación» $y$, por ende, inmunización no se está consiguiendo como consecuencia de la inoculación del HRAm?

- Yproporcionalidad: en el sentido de adopción de las medidas menos invasivas para la consecución del fin pretendido, así como el respeto de los principios básicos para las intervenciones administrativas restrictivas (ibid.: 14).

Es decir, que la obligatoriedad de la vacuna pasaría por la garantía de que su seguridad y frabilidad haya sido constatada. 


\section{RESPONSABILIDAD Y LEYES DE COMPENSACIÓN POR LOS DAÑOS Y PERJUICIOS EN LA SALUD PRODUCIDOS POR LAS VACUNAS}

Pues bien, ¿qué ocurre si esa seguridad y fiabilidad no existen? He aquí el nudo gordiano de la cuestión: la responsabilidad de los daños para la salud derivados de las "vacunas», sobre todo de las no suficientemente probadas y testadas, como es el caso de la COVID-19. ¿Quién debe asumir esta responsabilidad? ¿El Estado o las farmacéuticas? Si es una obligación que impone el Estado, lo suyo sería hablar de la responsabilidad patrimonial del Estado. Pero también podría argüirse que las farmacéuticas, empresas privadas, ponen a la venta un producto del que, en teoría, deberían garantizar su seguridad en un porcentaje elevadísimo, amén de una adecuada y comprensible información de los posibles efectos secundarios o adversos que, por demás, no se saben.

En la actualidad hay una veintena de países que cuentan con un sistema de compensación o reparación para las personas que, llevando una actitud diligente, hubiesen sufrido un daño como consecuencia de la vacunación, si bien, como es lógico para que el fabricante no pueda eludir su responsabilidad subsiste su deber de informar, «deber de advertir» (Tuells, 2013: 555).

Entre estos países está Alemania, Francia, Japón, Suiza, Dinamarca, Austria, Nueva Zelanda, Suecia, Gran Bretaña, Finlandia, Quebec, EE. UU., Taiwán, Italia, Corea, Noruega, Islandia, Eslovenia, Hungría y República Checa ${ }^{21}$. Precisamente por la existencia de estas leyes de compensación es más sencillo admitir la obligatoriedad de las vacunas en unos Estados, mientras que el debate es más intenso, en aquellos que eluden su responsabilidad patrimonial en caso de consecuencias negativas graves en la salud de los vacunados.

En la década de los ochenta se intentó resolver el problema de la responsabilidad de los laboratorios, debatiendo sobre la posibilidad de establecer un sistema de indemnización compensatoria, pero «sin admisión de responsabilidad o culpa», y sin eliminar la cláusula del «deber de advertir» (Tuells, 2013: 556).

En el escenario actual, las «vacunas» contra la COVID-19, por razones de urgencia, no han seguido todos los pasos que generalmente se imponen en los procesos de autorización de cualquier vacuna. Queda, pues, por resolver qué posibles efectos adversos pudiera tener en un futuro, ante la ausencia de los usuales ensayos clínicos con mayores garantías y más tiempo de análisis. He aquí la clave: la cuestión temporal para valorar los efectos adversos de los ensayos clínicos en un porcentaje adecuado de población y no en pequeñas muestras. Por tanto, se desconocen algunos efectos adversos. En España no hay una ley que

21 En estos países, la situación se decantó como consecuencia de los recelos de la población a vacunarse en la década de los setenta. Así, por ejemplo, en Alemania con la vacuna de la viruela, en Japón con la difteria, tétanos y tosferina o EE. UU. con la vacuna antipolio y gripe del cerdo y ahora con la de la COVID-19. Mientras que se calcula que en España el porcentaje de población que se negaría a inocularse la vacuna rondaría un escaso 5\%. 
prevea de forma específica la responsabilidad del Estado por los daños derivados de una imposición de la obligación de vacunarse, si bien hay algunos casos en que se han concedido indemnizaciones por los tribunales de justicia.

En España, como ya dijimos, se acoge el modelo de "recomendación", precisamente porque no existe una ley de compensación del daño que sería imprescindible para poder hablar de una vacunación obligatoria o, incluso, forzosa, hasta el punto de que los tribunales son reacios a indemnizar como consecuencia de los daños derivados de las vacunas. Así por ejemplo lo evidencian las sentencias del Tribunal Superior de Justicia de Castilla y León, que en 2004 admitía las secuelas por la vacuna de la viruela, administrada en 1975. Esto es: veintinueve años de peregrinación judicial. O los diecisiete de la sentencia de 2011, por vacunación de triple vírica a un menor de 15 meses, administrada en 1994 y que tuvo como resultado una discapacidad del $95 \%$.

Quizá por ello el TC, el 22 de julio de 2021, emitió la siguiente nota informativa (núm. 76/2021 el Pleno del TC por unanimidad en que acordaba mantener suspendido el precepto de la ley de salud de Galicia que impone la vacunación obligatoria Ley 8/2021, de 25 de febrero, de modificación de la Ley 8/2008, de 10 de julio, de salud de Galicia (DOG 26-2-2021) en que señalaba que:

El auto, cuyo ponente ha sido el magistrado Andrés Ollero, razona que la vacunación obligatoria no es una medida preventiva que aparezca expresamente contemplada en la Ley Orgánica 3/1986, de medidas especiales en materia de salud pública, y supone una intervención corporal coactiva y practicada al margen de la voluntad del ciudadano, que ha de someterse a la vacunación si se adopta esta medida, so pena de poder ser sancionado, en caso de negativa injustificada a vacunarse. Ello significa apreciar en este caso que el levantamiento de la suspensión del precepto impugnado sería susceptible de provocar perjuicios ciertos y efectivos que pueden resultar irreparables o de difícil reparación.

Por tanto, el Tribunal Constitucional está admitiendo que deberá ejercer una ponderación entre derechos privados y posibles intereses públicos en juego. Pero también debe tener en cuenta la ponderación de estos intereses en juego por la suspensión. Por ello, este Alto Tribunal es consciente de la concurrencia de los graves perjuicios de imposible o muy difícil reparación, que no pueden ser hipotéticos, sino posibles, probables e, incluso, presentes.

En definitiva, el Tribunal Constitucional debe efectuar su valoración, en primer lugar, de la constitucionalidad de la norma gallega. Es decir, ¿las medidas previstas en la ley gallega tienen perfecto engarce en la Ley Orgánica 3/1986, de medidas especiales en materia de salud pública? Será al hilo de este juicio de constitucionalidad donde podría insertarse el "hipotético» conflicto de derechos que ya hemos dicho, que no es tal. En este caso, la legislación gallega recurrida introduce obvias restricciones y limitaciones de derechos fundamentales, infringiendo así 
la reserva de ley orgánica en materia de desarrollo de derechos fundamentales (art. $81.1 \mathrm{CE}$ ). Asimismo, porque invade la competencia estatal exclusiva en materia de coordinación sanitaria (art. 149.1.16 CE). Además de que, en mi modesta opinión, la vacunación obligatoria no es una medida preventiva que es lo que expresamente se contemplaba en la Ley Orgánica 3/1986, de medidas especiales en materia de salud pública sino una obligación en toda regla que lleva aparejada la imposición de sanciones. Por tanto, no es previa, esto es, preventiva, sino sancionadora. Es más, el Consejo Interterritorial del Sistema Nacional Salud establece la voluntariedad de la vacunación, a diferencia de art. 41.bis d) de la Ley de salud de Galicia, que tipifica como infracción leve «la negativa injustificada al sometimiento a medidas de prevención consistentes en la vacunación o inmunización prescritas por las autoridades sanitarias, de acuerdo con lo establecido en la presente ley». Esa negativa puede calificarse como infracción grave, de acuerdo con el art. 42.bis c), cuando pudiera "producir un riesgo o un daño grave para la salud de la población», e incluso, de conformidad con el art. 43.bis d), como infracción muy grave si ese riesgo o daño grave se considera «muy grave». Pero una cosa será el aislamiento o confinamiento forzoso por mandamiento judicial y otra una vacunación sin garantías de seguridad para la salud de los receptores.

Toda vacunación supone una intervención corporal, que puede también poner en riesgo su vida y su integridad física. Por ello, el núm. $5^{\circ}$ del artículo 38.2.b) de la Ley 8/2008, de salud de Galicia (en la redacción resultante de la Ley 8/2021), supone una interferencia en las personas que afecta directamente al derecho garantizado por el artículo $15 \mathrm{CE}$, pues entiende como «medidas de control de las personas que estén o hayan estado en contacto con las personas enfermas» tales como la obligación de someterse «a medidas profilácticas de prevención de la enfermedad, incluida la vacunación o inmunización». Pero acudir al derecho a la vida como argumento es válido tanto para la vacunación obligatoria pero también es válida la posición contraria. Porque de igual modo se puede alegar la necesaria salud colectiva por la vacunación obligatoria de una «vacuna» nueva y no sometida a los cauces de la investigación científica, aprobada con urgencia en base de un tratamiento novedoso, que también podría poner en peligro la «salud pública o colectiva».

Por mucho que se insista, el riesgo siempre que se inocula una vacuna está2 ${ }^{2}$, al igual que cuando se toma cualquier medicamento, incluso una simple aspirina

22 Contamos con ejemplos tanto a nivel nacional como internacional. Así en el ámbito internacional: STEDH 12 marzo 2013. Caso Baytüre y otros c. Turquía. Negativa de los tribunales nacionales y las autoridades estatales a conceder una indemnización por el daño que había sufrido un menor de 3 meses (parálisis del pie derecho) derivado de la vacunación recomendada por las autoridades estatales, pero que no era obligatoria. El TEDH declaró inadmisible la demanda. O la DCEDH de 15 de enero de 1998. Caso Boffa and Others c. San Marino. Los demandantes se quejan de la existencia de leyes que obligan a los residentes de San Marino para someterse a vacunaciones Argumentan que el riesgo de muerte asociado con las vacunas es alto y alegan una violación del art. 2 CEDH 
puede producir una pericarditis, pero una cosa es este riesgo mínimo en vacunas testadas y lo suficientemente probadas, ensayadas tanto en chimpancés como en humanos y con tiempo de análisis suficiente para la valoración de los efectos secundarios. Otra bien distinta es el caso de la mal llamada "vacuna» contra la COVID-19, sobre la que apenas se sabe nada en cuanto a los posibles efectos adversos que pudiera producir en un futuro. Es más, entre la propia comunidad científica inmunológica se distingue entre tipos de vacunas y se pone el acento en los riesgos de vacunas como las de la gripe pandémica A (H1N1 (2009), la del papiloma humano por los importantes riesgos de infertilidad a ella asociados y obviamente sobre la COVID-19 (Tuells, 203: 556). Como recuerdan Di Pietro, Refolo y Gonzalez Melado (2012: 334 y 335), nunca debe perderse de vista el principio de responsabilidad política (y jurídica EGH) «a la hora de introducir nuevas vacunas o de proponer nuevas campañas de vacunación. Las decisiones políticas en materia de salud deben basarse en rigurosa evidencia científica, seguridad y costes de la nueva vacuna».

A todo lo expuesto debemos unir el dato de que la Unión Europea ha aprobado la conocida como «Estrategia sobre Opciones Terapéuticas contra la COVID-19, por lo que la Comisión selecciona cinco opciones terapéuticas candidatas prometedoras» (UE, 2021), que supone que la UE ha aprobado otras cinco opciones terapéuticas contra la COVID-19. Cuatro de estas son anticuerpos monoclonales que están sometidos a revisión continua por parte de la Agencia Europea de Medicamentos. La última es un inmunosupresor, que ya tiene la necesaria autorización para su comercialización. Parece, según anuncia la comisión, que, al menos, tres de estos nuevos tratamientos, esto es, medicamentos, se autorizarán en octubre de 2021 y los otros dos a finales de 2021. ¿Qué sentido tiene seguir hablando de la vacunación obligatoria?

\section{CONCLUSIONES}

Si ya contamos con tratamientos médicos, ¿por qué obligar a una vacunación que no cuenta con todas las garantías y que carece de toda la seguridad sobre las posibles consecuencias derivadas en un futuro? No debe perderse de vista, que la Agencia Europea del Medicamento aprobó la "vacuna» de la COVID-19 en fase de urgencia, lo que supone que, por mucho que se hayan reducido los plazos administrativos, los estudios clínicos de los posibles efectos secundarios que se realizan a los 24 meses, etc., no se han producido, sencillamente porque no han pasado esos 24 meses. Por lo tanto, es imposible afirmar que estas vacunas son

y también la DCEDH de 12 de julio de 1978. Caso Association of Parents c. Reino Unido La asociación demandante está formada por padres cuyos hijos han sufrido daños graves y duraderos o incluso han muerto como resultado de las vacunas. 
seguras y no producirán efectos negativos y perjudiciales contra la salud en un futuro.

Tal vez el debate deba trasladarse al de la desigualdad de los grupos y países más vulnerables que no tendrán acceso a estos tratamientos médico-terapéuticos. Si buscamos un ejemplo claro de globalización no hay más que ver cómo funciona un virus, que es el mayor ejemplo de globalización que existe junto con la crisis climática, etc., pues, por mucho que se intente evitar su propagación con pasaportes COVID $^{23}$ y restricciones a la libertad de movimientos, el virus seguirá propagándose, desde el momento en que no hemos sabido dar respuesta a otro de los grandes retos del mundo actual: la inmigración ilegal. Por ello, hablar de la obligatoriedad de la vacuna en el primer mundo es como intentar poner puertas al campo si no se garantiza la universalidad de las terapias preventivas y terapéuticas en países del tercer mundo que no tienen acceso. Por mucho que se imponga un pasaporte Covid-19, la inmigración ilegal es una realidad. En el momento en que uno solo de estos inmigrantes ilegales pise suelo español o europeo la propagación está servida.

\section{Bibliografía}

Beltrán Aguirre, J. L. (2012). Vacunas obligatorias y recomendadas: régimen legal y derechos afectados. DS: Derecho y salud, 22(1), 9-30.

Bird \& Bird \& COVID-19. (2021). HR Data Essentials. Vaccine guidance. BIRD \& BIRD, 20-9-2021. Disponible en: https://www.twobirds.com.in-focus.coronavirus.

Bombillar Sáenz, F. M. y Pérez Miras, A. (2015). El derecho a la protección de la salud desde una perspectiva multinivel y de Derecho comparado. Revista europea de derechos fundamentales, 25, 299-331.

Cierco Seira, C. (2021). La vacunación obligatoria y su eventual proyección sobre la covid-19. El Cronista del Estado Social y Democrático de Derecho, 93-94, 18-31.

Cobreros Mendazona, E. (2021). Salud pública y tratamientos sanitarios obligatorios. El Cronista del Estado Social y Democrático de Derecho, 93, 5-17.

Cortes Generales (1980). Trabajos Parlamentarios (Constitución española, T. I y II). Madrid: Cortes Generales.

De Miguel Beriain, I. y Santisteba Galarza, M. (2021). Pasaportes inmunológicos: un comentario ético-jurídico. El cronista del Estado Social y democrático de Derecho, 93-94, 46-51.

Di Pietro, Ma. L., Refolo, P. y González-Melado, F. J. (2012). Sobre la «responsabilidad» de la vacunación. Cuadernos de bioética, 23(2), 323-336.

23 Sobre esta cuestión también puede consultarse De Miguel Beriain y Santisteba Galarza (2021). 
Freixes Sanjuán, Ma T. (1984). Crónica de una Constitución consensuada. Revista de Estudios Políticos, 40, 99.

González Hernández, E. (2019). El debate constituyente sobre el Título I de la Constitución española de 1978, o la Constitución cenada. Historia constitucional: Revista Electrónica de Historia Constitucional, 20, 681-713. Disponible en: https:// doi.org/10.17811/hc.v0i20.595.

Herrero de Miñón, M. (1979). Falsas y verdaderas vías del consenso constitucional. Revista de Estudios Politicos, 9, 73-98.

Jiménez Villarejo, C. y Rodríguez-Aguilera, C. (1978). Las garantías de los derechos humanos en el actual proceso constituyente. La izquierda y la Constitución. Barcelona: Taula de Canvi.

Klinger, J. C. y Sánchez Bonilla, A. L. (2000). Inmunología Antiviral. Revista Facultad Ciencias de la Salud: Universidad del Cauca, 2(1), 27-33.

Marrugat, J., Vila, J., Pavesi, M. y Sanz, F. (2016). Estimación del tamaño de la muestra en la investigación clínica y epidemiológica. En II Seminario sobre Epidemiología Clínica y Molecular del Cáncer, "Epidemiología genética y molecular. Fundamentos, diseños y estrategias de análisis». Barcelona

Martín Ayala, M. (2014). Vacunación infantil. Derecho y salud, 24(1), 182-192.

Organización Mundial de la Salud. (2021). Preguntas más frecuentes. Disponible en: https://bit.ly/3beQMuR.

Palmero, F. (2019). Siete 'padres' de la Constitución que pudieron ser nueve. El Mundo, 6-12-2018. Disponible en: https://bit.ly/3EmFSzA.

Pérez-Llorca, J. P. (2018). ¿Balance o liquidación? En B. Pendás (dir.), E. González y R. Rubio (coords.). España constitucional (1978-2018). Trayectorias y perspectivas (pp. 53-67). Madrid: Centro de Estudios Políticos y Constitucionales.

Powell, C. T. (2001). España en democracia (1975-2000). Barcelona: Plaza y Janés.

Presno Linera, M. (2021). Sobre la vacunación del personal sociosanitario en Italia y España. El derecho y el revés [blog], 7-4-2021. Disponible en: https://bit. ly/3pKCDxU.

Ruiz Sáenz, A. (2011). Intervenciones obligatorias por riesgo de transmisión de enfermedades contagiosas: interés público versus derechos individuales. Derecho y salud, 21(2), 171-178.

Sánchez Bustelo, A. (2004). Viajes y vacunas: una precaución necesaria. NURE investigación: Revista Cientifica de enfermeria, 7, 6.

Sarrión Esteve, J. (2021). La competencia de las autoridades sanitarias para restringir derechos en situación de crisis sanitaria. Gaceta Sanitaria. Disponible en: https://bit.ly/3mfWhji.

Tuells, J. (2013). Razones para un programa de compensación de daños por acontecimientos adversos relacionados con vacunas en España. Medicina Clínica, 140(12), 554-557. Disponible en: https://doi.org/10.1016/j.medcli.2013.01.043.

Unión Europea (2021). Estrategia sobre Opciones Terapéuticas contra la COVID-19: la Comisión selecciona cinco opciones terapéuticas candidatas prometedoras. Disponible en: https://bit.ly/3vQIIPH. 
Vasak. K. (1977). 30-Year Struggle-Sustained Efforts to give Force of Law to UNIVERSAL-DECLARATION-OF-HUMAN-RIGHTS. UNESCO courier, (10), 28.

VV. AA. (2020). El coronavirus y otros problemas. El cronista del Estado Social y democrático de Derecho, 86/87

Wise, C. (2021). Covid-19: France and Greece make vaccination mandatory for healthcare workers. The British Medical Journal, 1797. Disponible en: https:// bit.ly/2ZCaXk5.

STS, de su Sala de lo Contencioso-Administrativo Sección Cuarta Sentencia 1.112/2021, de 14/09/2021.

Tribunal Europeo de Derechos Humanos (2021). Disponible en: https://bit.ly/2ZrcD$\mathrm{Ny}$. 